\title{
Comparative quality measures of emergency care: an outcome cockpit proposal to survey clinical processes in real life
}

This article was published in the following Dove Press journal:

Open Access Emergency Medicine

24 October 2017

Number of times this article has been viewed

\author{
Susanne Burgemeister ${ }^{\prime}$ \\ Alexander Kutz' \\ Antoinette Conca ${ }^{2}$ \\ Thomas Holler ${ }^{3}$ \\ Sebastian Haubitz' \\ Andreas Huber ${ }^{4}$ \\ Ulrich Buergi ${ }^{5}$ \\ Beat Mueller' \\ Philipp Schuetz' \\ 'University Department of Internal \\ Medicine, Medical Faculty of the \\ University of Basel, Kantonsspital \\ Aarau, Basel, ${ }^{2}$ Department of Clinical \\ Nursing Science, ${ }^{3}$ Department of \\ Controlling and Quality Management, \\ ${ }^{4}$ Department of Laboratory \\ Medicine, ${ }^{5}$ Emergency Department, \\ Kantonsspital Aarau, Aarau, \\ Switzerland
}

Correspondence: Philipp Schuetz University Department of Internal Medicine, Kantonsspital Aarau, Tellstrasse, $\mathrm{CH}-500 \mathrm{I}$ Aarau, Switzerland Email schuetzph@gmail.com
Background: Benchmarking of real-life quality of care may improve evaluation and comparability of emergency department (ED) care. We investigated process management variables for important medical diagnoses in a large, well-defined cohort of ED patients and studied predictors for low quality of care.

Methods: We prospectively included consecutive medical patients with main diagnoses of community-acquired pneumonia, urinary tract infection (UTI), myocardial infarction (MI), acute heart failure, deep vein thrombosis, and COPD exacerbation and followed them for 30 days. We studied predictors for alteration in ED care (treatment times, satisfaction with care, readmission rates, and mortality) by using multivariate regression analyses.

Results: Overall, 2986 patients (median age 72 years, 57\% males) were included. The median time to start treatment was 72 minutes (95\% CI: 23 to 150), with a median length of ED stay (ED LOS) of 256 minutes (95\% CI: 166 to 351). We found delayed treatment times and longer ED LOS to be independently associated with main medical admission diagnosis and time of day on admission (shortest times for MI and longest times for UTI). Time to first physician contact ( -0.01 hours, $95 \%$ CI: -0.03 to -0.02 ) and ED LOS ( -0.01 hours, $95 \%$ CI: -0.02 to -0.04$)$ were main predictors for patient satisfaction.

Conclusion: Within this large cohort of consecutive patients seeking ED care, we found time of day on admission to be an important predictor for ED timeliness, which again predicted satisfaction with hospital care. Older patients were waiting longer for specific treatment, whereas polymorbidity predicted an increased ED LOS.

Keywords: quality measures, quality of care, emergency department, length of stay, patient satisfaction, benchmarking, health care service

\section{Introduction}

The complexity of patients seeking for emergency department (ED) care is increasing because of populations' demographic change and more sophisticated treatment strategies, especially in polymorbid patients. Accordingly, cost-effectiveness of hospitals and EDs must be optimized, and the capacity of hospital beds is reduced due to cost cuts in the health care systems. Overcrowding of EDs is related to increased mortality. ${ }^{1-3}$ To improve triage of incoming patients, attempts focusing ${ }^{4-7}$ on the initial triage system, fast track areas, ${ }^{8,9}$ worksite nurse practitioners, ${ }^{10}$ and “Quick Diagnostic Units" among others have been tested. ${ }^{11}$ To improve cost-effectiveness of inpatient treatment, many countries including Switzerland have introduced payment systems based on diagnosisrelated groups (DRGs). These provide incentives for hospitals to reduce inpatient care, but their effect on overall budgets remains controversial. ${ }^{4-7}$ 
Benchmarking allows comparisons and serves to motivate providers to improve care and, thus, represents a measurable surrogate of excellence. The US Qualitynet relies on hospital data submitted by every participating hospital in a standardized way. The database reports averages for different benchmark parameters where hospitals can compare their own data to other institutions across the country. ${ }^{12}$

Quality of care includes health outcomes, process variables in disease management (e.g., treatment times), and subjective measures such as patient satisfaction. In 2001, the Institute of Medicine has defined six domains for high quality of care: ${ }^{13}$ safe, effective, patient-centered, timely, efficient, and equitable, which were supported by the WHO in 2006. These factors must be adapted to different clinical settings due to differences in care priorities. In the ED setting, timeliness of initial treatment and effectiveness of care have highest priority because shorter time to treatment has been linked to improved outcomes in several diseases including stroke, ${ }^{14}$ sepsis, ${ }^{15}$ myocardial infarction (MI) ${ }^{16}$ and pneumonia. ${ }^{17,18}$ In 2006, first results of the Performance Measures and Benchmarking Summit were published ${ }^{20}$ and updated in $2011 .{ }^{20}$ Common definitions of key terms, time stamps, and metrics should improve comparability between EDs and therefore facilitate further research and the implementation of guidelines.

Many articles on ED performance measurement are focusing on only one single indicator or describe an arguably representative selection of time measures. Most studies are systematic reviews of specific performance indicators in homogeneous conditions such as trauma care ${ }^{21}$ or for ED management of pneumonia. ${ }^{17,18,22}$ Conversely, a recent prospective analysis focused on more broad aspects of ED care in polymorbid patients with acute infections, a main reason for ED admission. ${ }^{23}$

Regarding patients' satisfaction with ED care, there exist only few studies and often patients are not asked about their subjective experiences during contact with health care personnel. Also for clinicians, it is unusual to ask for feedback and to implement such questions in their daily business. Although some studies have looked at satisfaction of care, there is a general lack of knowledge regarding which factors contribute to low satisfaction. ${ }^{24-26}$ Identification of such factors may help to define preventive strategies. Timeliness (time to first physician contact, overall waiting time, ED length of stay [LOS]) is an important process management variable and predicts satisfaction as well as willingness to return to an $\mathrm{ED}$ in the future. ${ }^{27-29}$

Although there is a general agreement on the importance of providing high-quality care to patients and also on measuring and reporting this quality, there is a lack of internationally accepted set of quality variables for use in daily "real life" in the ED setting. Herein, our aim was to investigate different process management variables and quality indicators for six important medical diagnoses in a consecutive, large, and well-defined ED patient cohort and to study predictors for low quality of ED care including low satisfaction with care.

\section{Methods \\ Study design}

This report adheres to the STROBE guidelines for reporting observational studies. ${ }^{30} \mathrm{We}$ used data entered into the TRIAGE database, a prospective, observational cohort study. ${ }^{31}$ During the period between June 2013 and June 2015, we included consecutive medical patients presenting with a medical urgency at the Cantonal Hospital in Aarau (Switzerland), a 600-bed tertiary care hospital with $75 \%$ of medical admissions entering the hospital requiring treatment in the ED. As an observational quality control study, the Institutional Review Board (IRB) of Cantonal Hospital approved the study and waived the need for individual informed consent (Ethikkommission Kanton Aargau [EK 2012/059]). The study (NCT01768494) was registered at the "ClinicalTrials.gov" registration website (http://www. clinicaltrials.gov/ct2/show/NCT01768494) and the study protocol has been published previously. ${ }^{32}$ In brief, the TRIAGE database includes consecutive, adult patients who were included upon ED admission. We measured several clinical and process variables in these patients and followed them during the hospital stay and contacted them after 30 days for a standardized telephone interview. The main objective was to find prognostic biomarkers to risk stratify patients. . $3,31,33-35^{-3}$

\section{Overall research aim}

We aimed first to study quality measures of ED care including timeliness, patient outcome, and satisfaction, and second to identify predictors for low quality care. We focused on six important and frequent main diagnoses, namely, communityacquired pneumonia (CAP), urinary tract infection (UTI), MI, acute heart failure (HF), deep vein thrombosis and/or pulmonary embolism (DVT/PE), and exacerbation of chronic obstructive pulmonary disease (COPD).

\section{Patient sample and data collection}

Upon ED admission, consecutive patients with one of the six main admission diagnoses were assessed by a triage nurse, and initial triage priority was assigned based on the 
routine hospital algorithm, in our case the German version of the 5-level Manchester Triage Score (MTS). ${ }^{36}$ All participants provided a medical history and underwent a physical examination with measurement of vital signs. We recorded main presenting clinical symptoms and complaints, sociodemographics, and comorbidities. We collected several time stamps as: time to first physician contact, time to treatment, time to diagnostic procedures, time until the documents for patient transfer are completed, and overall ED LOS. We also asked patients about their satisfaction with care at ED discharge using a visual analog scale from 0 (very poorly) to 100 points (highly satisfied). We recorded the number of active diagnoses on admission as a measure of comorbidity. Active diagnoses were defined as diagnoses with the need for special treatment during hospital stay, for example, a not well-controlled hypertension with the need for adjustment of drugs or a well-controlled hypertension was not recorded. We also recorded times of day in all patients and categorized the variable into daytime (between 07.00 am and 12.59 pm), afternoon (between $01.00 \mathrm{pm}$ and $06.59 \mathrm{pm}$ ), evening (between $07.00 \mathrm{pm}$ and $00.59 \mathrm{am}$ ), and night (between 1.00 am and $06.59 \mathrm{am})$.

During the hospital stay, staff physicians, nurses, and social care workers managed the patients according to the underlying medical condition and in compliance with hospital guidelines without any intervention of the research team. All patients were contacted 30 days after hospital admission for a detailed telephone interview with a predefined questionnaire to assess vital and functional status, unplanned hospital readmission or general practitioner (GP) visit, quality of life, care needs at home, and satisfaction with provided in-hospital care and discharge procedure. If patients could not be reached or could not provide the needed information, close relatives caring for the patients were asked.

\section{Statistical analysis}

Discrete variables are expressed as counts (percentage) and continuous variables as medians with interquartile ranges (IQR). Frequency comparison was done by the chi-square test. For two-group comparisons, the Mann-Whitney $U$-test was used. We used multivariable regression models to examine the association of several baseline characteristics with outcomes, namely, time to treatment, LOS in ED, and patient satisfaction. As predefined, regression models were adjusted for age and gender, number of active diagnoses, and time of day on admission. Analyses were performed with Stata 12.2 (StataCorp LP, College Station, TX, USA).

\section{Results}

\section{Baseline}

A total of 2986 patients (median age 72 years, $43.7 \%$ of patients females) were included. Detailed baseline data are presented in Table 1 and stratified according to one of the six main diagnoses. The main diagnoses were CAP in $21.2 \%$ of the patients, UTI in $14.1 \%$, MI in $30.2 \%$, HF in $15.2 \%$, DVT/ $\mathrm{PE}$ in $9.6 \%$, and COPD in $9.5 \%$. Patients had a high burden of comorbidities including hypertension (45.7\%), coronary heart disease $(26.2 \%)$, chronic heart failure $(21.7 \%)$, diabetes (14.5\%), and COPD (14.3\%). Patients showed some differences across diagnoses with regard to gender, number of active diagnoses, and also acuity of initial presentation according to MTS. Most of the patients arrived during the daytime to the ED $(32.8 \%$ in the morning and $35.1 \%$ from noon to $6 \mathrm{pm}$ ), while from midnight to early morning only $13.4 \%$ of the patients were registered.

\section{Quality of care}

Table 2 shows an overview of outcome parameters within the main diagnoses. Overall, median ED LOS was 256 minutes, the time to treatment 72 minutes, and satisfaction with care 90 points with a maximum of 100 points. With regard to adverse outcome within 30 days of ED admission, $8.9 \%$ of patients were admitted to intensive care unit (ICU), $5.1 \%$ died in the hospital, and $6.8 \%$ died within 30 days after admission. When looking at the different diagnoses, there were significant differences between all timeliness measures. While patients with MI had the shortest treatment times, time to treatment (antibiotics) in CAP and UTI were longest.

\section{Association of baseline factors and quality of care}

As shown in Table 3, time of day predicted timeliness with shorter time to effective treatment during the night time of -21 minutes ( $95 \% \mathrm{CI}:-37.5$ to $-4.6, p=0.012$ ) compared to morning hours. Also, age was a predictor for longer time to treatment, 4 minutes (95\% CI: 0.4 to 7.5$)$ longer for every 10 years of age, $p=0.028$. Time to effective treatment was longest during daytime (between 07.00 am and $12.59 \mathrm{pm}$ ), and in all other times of day the overall stay was shorter: 01.00 pm to $06.59 \mathrm{pm}:-42.9$ minutes (95\% CI: 61.1 to -24.8 , $p=<0.001)$; $07.00 \mathrm{pm}$ to $00.59 \mathrm{am}:-39.6$ minutes (95\% CI: -61.5 to $-16.6, p=0.001) ; 01.00$ am to 06.59 am: -39.5 minutes (95\% CI: -65.5 to $-13.5, p=0.003)$. Also, timeliness depended on the main diagnoses, with shortest times for MI 
Table I Baseline characteristics

\begin{tabular}{|c|c|c|c|c|c|c|c|}
\hline Characteristics & Overall & CAP & UTI & MI & HF & DVT/PE & COPD \\
\hline $\mathrm{N}(\%)$ & $2986(100)$ & $634(21.2)$ & $422(14.1)$ & $903(30.2)$ & $455(15.2)$ & $288(9.6)$ & $284(9.5)$ \\
\hline Age, $n$ median (IQR) & $72(60,81)$ & $72(6 I, 8 I)$ & $76(61,83)$ & $65(56,76)$ & $81(72,86)$ & $71.5(57,80)$ & $72(63,80)$ \\
\hline Gender, female $\mathrm{n}(\%)$ & $1299(43.5)$ & $279(44.0)$ & $299(70.9)$ & $252(27.9)$ & $184(40.4)$ & $16 \mid(55.9)$ & $124(43.7)$ \\
\hline Gender, male n (\%) & $1687(56.5)$ & $355(56.0)$ & I $23(29.1)$ & $65 I(72.1)$ & $27 \mid(59.6)$ & $127(44.1)$ & $160(56.3)$ \\
\hline \multicolumn{8}{|c|}{ No of diagnosis to treat, $n(\%)$} \\
\hline I & $620(20.9)$ & $59(9.4)$ & $78(18.6)$ & $345(38.5)$ & $30(6.6)$ & $53(18.5)$ & $55(19.5)$ \\
\hline 2 & $771(26.0)$ & $145(23.1)$ & $95(22.6)$ & $27 \mid(30.2)$ & $94(20.8)$ & $91(31.7)$ & $75(26.6)$ \\
\hline 3 & $722(24.3)$ & $184(29.3)$ & $109(26.0)$ & $167(18.6)$ & $118(26.0)$ & $79(27.5)$ & $65(23.0)$ \\
\hline 4 & $400(13.5)$ & $116(18.5)$ & $59(14.0)$ & $66(7.4)$ & $84(18.5)$ & $36(12.5)$ & $39(13.8)$ \\
\hline$\geq 5$ & $453(15.3)$ & $124(19.7)$ & 79 (18.8) & $47(5.2)$ & $127(28.0)$ & $28(9.8)$ & $48(17.0)$ \\
\hline \multicolumn{8}{|l|}{ MTS, n (\%) } \\
\hline Red & $33(1.8)$ & $6(1.5)$ & $\mathrm{I}(0.3)$ & $18(4.5)$ & $4(1.3)$ & I (0.5) & $3(1.6)$ \\
\hline Orange & $528(29.4)$ & $89(22.0)$ & $25(8.6)$ & $244(60.5)$ & 71 (23.4) & $44(21.5)$ & $55(28.6)$ \\
\hline Yellow & $782(43.5)$ & $213(52.6)$ & $135(46.6)$ & $104(25.8)$ & $146(48.2)$ & $88(42.9)$ & $96(50.0)$ \\
\hline Green & $436(24.2)$ & $94(23.2)$ & $120(4 \mid .4)$ & $37(9.2)$ & $79(26.1)$ & $72(35.1)$ & 34 (I7.7) \\
\hline Blue & $19(1.1)$ & $3(0.7)$ & $9(3.1)$ & $0(0.0)$ & $3(1.0)$ & $0(0.0)$ & $4(2.1)$ \\
\hline \multicolumn{8}{|c|}{ Place of first treatment, $n$ (\%) } \\
\hline ED & $2709(97.4)$ & $584(98.2)$ & $398(99.3)$ & $776(94.5)$ & $416(98.6)$ & $272(98.9)$ & $263(98.1)$ \\
\hline Resuscitation room & $73(2.6)$ & II (I.8) & $3(0.7)$ & $45(5.5)$ & $6(1.4)$ & $3(I . I)$ & $5(1.9)$ \\
\hline \multicolumn{8}{|c|}{ Vital signs, median (IQR) } \\
\hline Systolic BP, mmHg & $143(125,159)$ & $136(120,152)$ & $139(121,153)$ & $148(|3|, \mid 66)$ & $140(123,159)$ & $147(129,162.5)$ & $146(129,159)$ \\
\hline Diastolic BP, mmHg & $83(72,95)$ & $78(68,89)$ & $79(69,89)$ & $90(79,100)$ & $8 I(7 I, 94)$ & $86(76,99)$ & $87(77,97)$ \\
\hline Saturation without & $95.0(91.0,97.0)$ & $93.0(89.6,95.6)$ & $95.3(93.0,98.0)$ & $96.0(94.0,98.0)$ & $94.0(90.0,96.0)$ & $95.0(92.0,97.0)$ & $93.0(88.0,95.4)$ \\
\hline \multicolumn{8}{|c|}{ 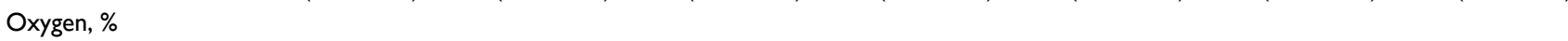 } \\
\hline Pulse rate, bpm & $87(73,102)$ & $94(81,109)$ & $88(76,100)$ & $77(67,91)$ & $83(70,100)$ & $87(75,103)$ & $94(80,106)$ \\
\hline Respiration rate/min & $19.9(16.0,24.0)$ & $23.8(19.0,28.0)$ & $19.0(16.0,26.0)$ & $17.0(14.0,20.0)$ & $21.0(18.0,24.0)$ & $22.0(19.0,25.0)$ & $20.8(17.6,24.0)$ \\
\hline Body temperature, ${ }^{\circ} \mathrm{C}$ & $37.1(36.6,37.9)$ & $38(37.2,38.8)$ & $37.5(37,38.6)$ & $36.6(36.3,37)$ & $36.8(36.4,37.2)$ & $37.1(36.6,37.5)$ & $37.1(36.7,37.7)$ \\
\hline \multicolumn{8}{|c|}{ Secondary diagnosis, $\mathbf{n}(\%)$} \\
\hline Obesity & $240(8.0)$ & $44(6.9)$ & $17(4.0)$ & $88(9.7)$ & $4 \mid(9.0)$ & $25(8.7)$ & $25(8.8)$ \\
\hline Alcohol abuse & $36(1.2)$ & $9(1.4)$ & $5(1.2)$ & $4(0.4)$ & $7(1.5)$ & $I(0.3)$ & $10(3.5)$ \\
\hline Anemia & $266(8.9)$ & $95(15.0)$ & $39(9.2)$ & $30(3.3)$ & $5 I(I I .2)$ & $27(9.4)$ & $24(8.5)$ \\
\hline $\mathrm{HF}$ & $649(21.7)$ & $70(11.0)$ & $13(3.1)$ & $76(8.4)$ & $455(100.0)$ & $13(4.5)$ & $22(7.7)$ \\
\hline COPD & $428(14.3)$ & $73(11.5)$ & $10(2.4)$ & $18(2.0)$ & $33(7.3)$ & $10(3.5)$ & $284(100.0)$ \\
\hline Dementia & $77(2.6)$ & $18(2.8)$ & $25(5.9)$ & $8(0.9)$ & $14(3.1)$ & $7(2.4)$ & $5(1.8)$ \\
\hline Diabetes type 2 & $432(14.5)$ & $80(12.6)$ & $43(10.2)$ & $152(16.8)$ & $101(22.2)$ & $22(7.6)$ & $34(12.0)$ \\
\hline $\begin{array}{l}\text { Gastrointestinal } \\
\text { diseases }\end{array}$ & $234(7.8)$ & $63(9.9)$ & $42(10.0)$ & $52(5.8)$ & $32(7.0)$ & $17(5.9)$ & $28(9.9)$ \\
\hline Hypertension & $1366(45.7)$ & $257(40.5)$ & $122(28.9)$ & $475(52.6)$ & $306(67.3)$ & $88(30.6)$ & I I 8 (4I.5) \\
\hline Infection & $528(17.7)$ & $210(33.1)$ & $203(48.1)$ & $30(3.3)$ & $4 \mid(9.0)$ & $13(4.5)$ & $31(10.9)$ \\
\hline $\mathrm{CHD}$ & $782(26.2)$ & $15(2.4)$ & $2(0.5)$ & $715(79.2)$ & $32(7.0)$ & $6(2.1)$ & $12(4.2)$ \\
\hline Stroke & $60(2.0)$ & $16(2.5)$ & $9(2.1)$ & $17(1.9)$ & II (2.4) & $4(1.4)$ & $3(1.1)$ \\
\hline Tumor & $253(8.5)$ & $110(17.4)$ & $35(8.3)$ & II (I.2) & $24(5.3)$ & $49(17.0)$ & $24(8.5)$ \\
\hline \multicolumn{7}{|l|}{ diseases } & $25(8.8)$ \\
\hline \multicolumn{8}{|l|}{ Time, n (\%) } \\
\hline $07.00 \mathrm{am}-12.59 \mathrm{pm}$ & $925(32.8)$ & $214(34.5)$ & $89(2 \mid .2)$ & $269(35.3)$ & $166(37.0)$ & $90(31.5)$ & $97(34.3)$ \\
\hline $01.00 \mathrm{pm}-06.59 \mathrm{pm}$ & $990(35.1)$ & $227(36.6)$ & $140(33.4)$ & $245(32.2)$ & $174(38.8)$ & $|2|(42.3)$ & $83(29.3)$ \\
\hline $07.00 \mathrm{pm}-00.59 \mathrm{am}$ & $527(18.7)$ & $120(19.3)$ & $107(25.5)$ & $125(16.4)$ & $64(14.3)$ & $53(18.5)$ & $58(20.5)$ \\
\hline $01.00 \mathrm{am}-06.59 \mathrm{am}$ & $378(13.4)$ & $60(9.7)$ & $83(19.8)$ & $123(16.1)$ & $45(10.0)$ & $22(7.7)$ & 45 (I5.9) \\
\hline
\end{tabular}

Abbreviations: IQR, interquartile range; MTS, Manchester Triage System; ED, emergency department; BP, blood pressure; CAP, community-acquired pneumonia; HF, acute heart failure; UTI, urinary tract infection; MI, myocardial infarction; DVT/PE, deep vein thrombosis and/or pulmonary embolism; COPD, chronic obstructive pulmonary disease; CHD, coronary heart disease. 


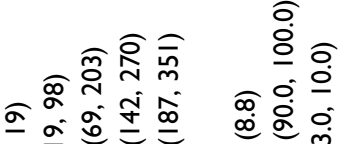

कि

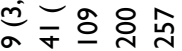

+0 宊

영요은

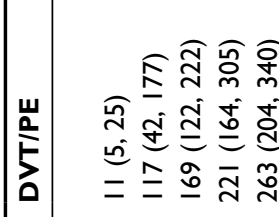

응

o

कृ

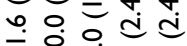

(

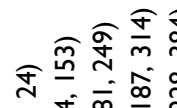

ले क्ष

응

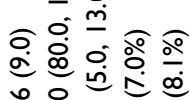

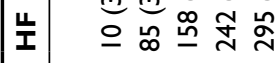

ळ.

응

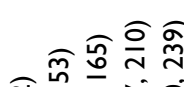

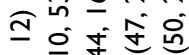

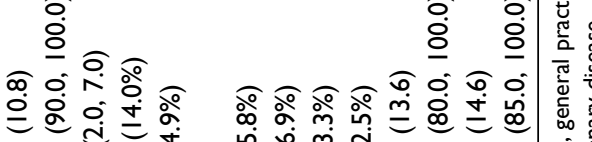

$\bar{\Sigma}$ एᄂ

๙

ชิ

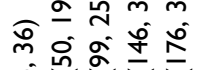

5

드으.

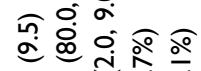

영용

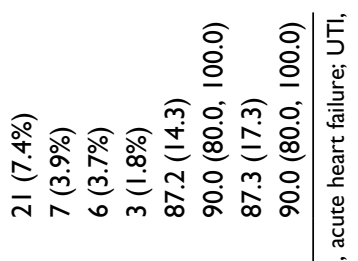

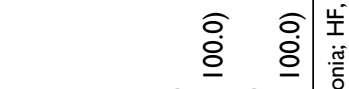

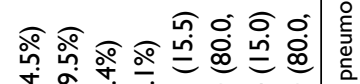

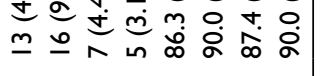

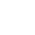

종ํㅇ

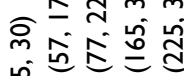

홍

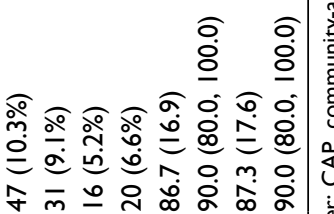

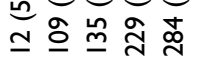

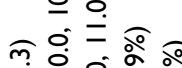

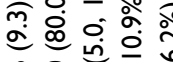

త్

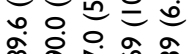

每

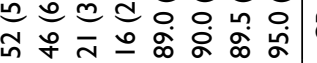

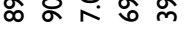

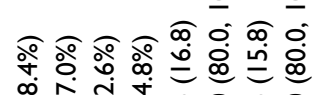

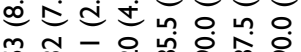

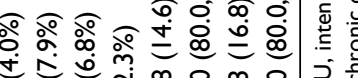

닌

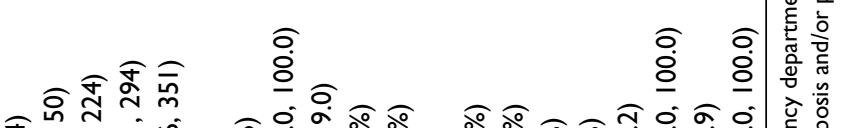

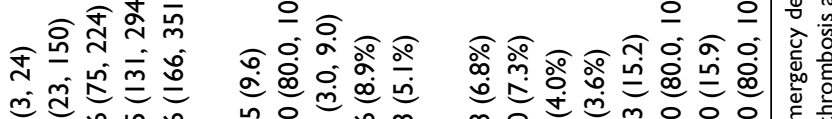

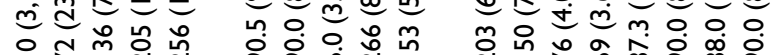

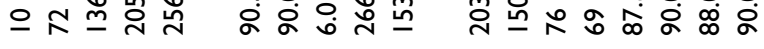

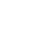

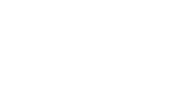

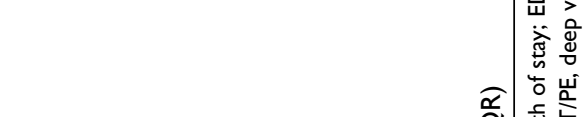

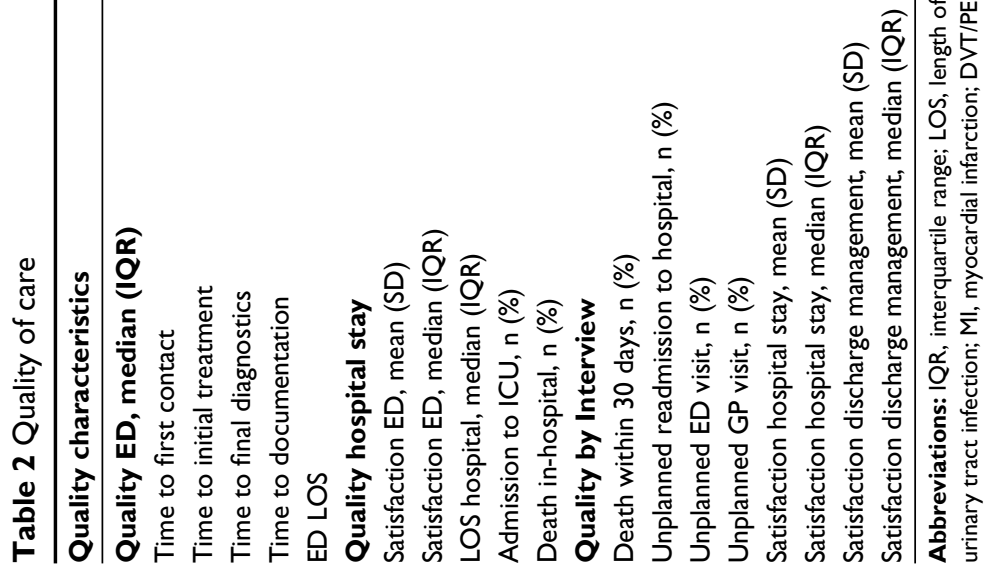




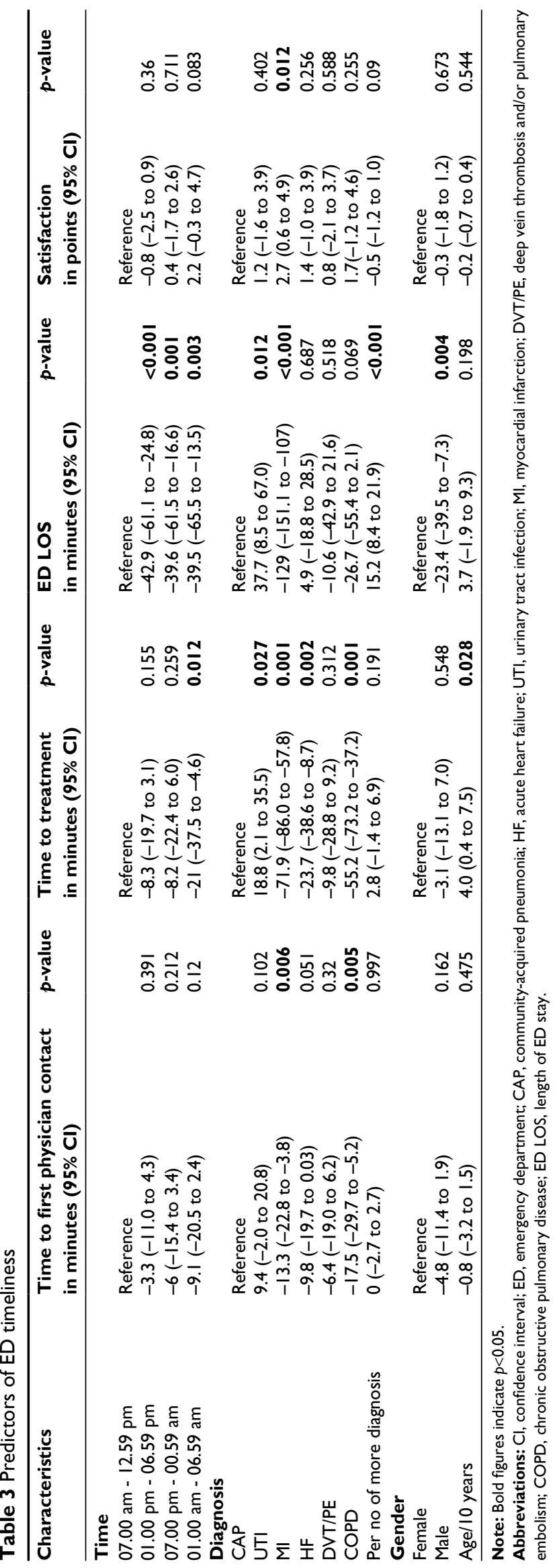

patients (time to treatment -71.9 minutes [95\% CI: -86.0 to $-57.8, p=0.001]$ and ED LOS -129 minutes [95\% CI: -151.1 to $-107.0, p<0.001])$ and the longest time for patients with UTI (time to treatment +18.8 minutes [95\% CI: 2.1 to 35.5 , $p=0.027$ ] and ED LOS +37.7 minutes [95\% CI: 8.5 to 67.0 , $p=0.012]$ ). Additionally, we found polymorbidity - mirrored in the number of active diagnoses - was a predictor for longer ED LOS with 15 minutes increase (95\% CI: 8.4 to 21.9) per additional active diagnosis $(p<0.001)$.

As independent variables, we included treatment times into the multivariable regression model to focus on patients' satisfaction. Herein, shorter time to first physician contact and shorter length of stay in the ED were significant predictors for satisfaction with care (regression coefficient -0.01 [95\% CI: -0.03 to -0.002 ] and -0.01 [95\% CI: -0.02 to -0.004 ], respectively) (Table 4 ).

\section{Discussion}

Within this relatively large cohort of consecutive ED patients with one of the six common main medical diagnoses, we studied process variables and quality parameters as well as predictors for low quality of care. We found five predictors to be associated with quality of ED care, which may help to derive preventive strategies in the near future.

The first and most important predictor in our setting was the time of day on arrival. ED LOS was longest in the morning, when about one-third of the patients arrived and thus crowding may have been an issue. In the last years, efforts have been made to create and establish criteria for ED timeliness, for example, in the United Kingdom and in Australia with a goal of $<240$ minutes $^{37}$ and $<360$ minutes in New Zealand. However, focusing on a single time stamp does not automatically correspond to higher quality of care and may lead to wrong priorities in patient care..$^{38}$ If patients are transferred to other wards without adequate therapy or without receiving necessary diagnostic examinations, timeliness may appear better, but the quality of care would be flawed. Still, our data suggest higher staffing in the morning hours could have a potential influence on reducing ED LOS and thereby improve satisfaction of patients.

Second, due to lower number of patient visits, we found the shortest time to treatment during the night. Apparently, the limited availability of care providers is compensated with an even more limited patient load or more efficient and simplified process variables during off-peak hours. In this context, one important quality indicator is time to treatment with different reports showing that longer waiting time to effective treatment negatively affects outcome. ${ }^{39-41}$ Still, 
Table 4 Predictors for patients' satisfaction

\begin{tabular}{|c|c|c|c|c|c|c|c|c|}
\hline $\begin{array}{l}\text { Included } \\
\text { characteristics } \\
\text { satisfaction points }\end{array}$ & $\begin{array}{l}\text { Time to first } \\
\text { physician } \\
\text { contact } \\
\text { in points } \\
(95 \% \mathrm{Cl})\end{array}$ & $p$-value & $\begin{array}{l}\text { Time to } \\
\text { treatment } \\
\text { in points } \\
(95 \% \mathrm{CI})\end{array}$ & $p$-value & $\begin{array}{l}\text { ED LOS } \\
\text { in points } \\
(95 \% \mathrm{Cl})\end{array}$ & $p$-value & $\begin{array}{l}\text { Time to } \\
\text { diagnostics } \\
\text { in points } \\
(95 \% \mathrm{Cl})\end{array}$ & $p$-value \\
\hline Overall & $\begin{array}{l}-0.01 \\
(-0.03 \text { to }-0.002)\end{array}$ & 0.028 & $\begin{array}{l}0.01 \\
(-0.02 \text { to } 0.0009)\end{array}$ & 0.074 & $\begin{array}{l}-0.01 \\
(-0.02 \text { to }-0.004)\end{array}$ & 0.005 & $\begin{array}{l}0.01 \\
(-0.02 \text { to } 0.001)\end{array}$ & 0.102 \\
\hline \multicolumn{9}{|l|}{ Time } \\
\hline $07.00 \mathrm{am}-12.59 \mathrm{pm}$ & Reference & & Reference & & Reference & & Reference & \\
\hline $01.00 \mathrm{pm}-06.59 \mathrm{pm}$ & $-1.9(-4.2$ to 0.4$)$ & 0.107 & $-2.8(-5.1$ to -0.5$)$ & 0.019 & $-1.9(-4.6$ to 0.8$)$ & 0.173 & $-2.4(-5.3$ to 0.5$)$ & 0.102 \\
\hline $07.00 \mathrm{pm}-00.59 \mathrm{am}$ & $0.2(-2.7$ to 3.0$)$ & 0.905 & $0.5(-2.4$ to 3.3$)$ & 0.74 & $0.7(-2.6$ to 4$)$ & 0.659 & $0.5(-3.2$ to 4.2$)$ & 0.779 \\
\hline $01.00 \mathrm{am}-06.59 \mathrm{am}$ & $1.4(-2.0$ to 4.8$)$ & 0.408 & $1.9(-1.4$ to 5.2$)$ & 0.267 & $1.2(-2.6$ to 4.9$)$ & 0.539 & $3(-1.6$ to 7.6$)$ & 0.204 \\
\hline \multicolumn{9}{|l|}{ Diagnosis } \\
\hline CAP & Reference & & Reference & & Reference & & Reference & \\
\hline UTI & $1.2(-2.4$ to 4.8$)$ & 0.513 & 2.2 (-1.3 to 5.7$)$ & 0.212 & $1.2(-3.3$ to 5.7$)$ & 0.601 & 0.7 (-4.0 to 5.3$)$ & 0.775 \\
\hline MI & $2(-0.8$ to 4.8$)$ & 0.166 & $1.2(-1.7$ to 4.1$)$ & 0.428 & -0.3 (-3.7 to 3.1$)$ & 0.863 & $2(-1.7$ to 5.7$)$ & 0.283 \\
\hline $\mathrm{HF}$ & $0.4(-2.6$ to 3.5$)$ & 0.78 & $0.3(-2.8$ to 3.5$)$ & 0.834 & $-0.8(-4.5$ to 2.8$)$ & 0.651 & $1.3(-2.8$ to 5.4$)$ & 0.527 \\
\hline DVT/PE & $-1.3(-5.2$ to 2.5$)$ & 0.488 & -2.1 (-6.0 to I.7) & 0.276 & $1.3(-3.5$ to 6$)$ & 0.597 & $-0.7(-5.3$ to 3.8$)$ & 0.756 \\
\hline COPD & $2.2(-1.6$ to 5.9$)$ & 0.258 & $1.8(-2.0$ to 5.6$)$ & 0.347 & $1.7(-2.6$ to 5.9$)$ & 0.438 & I $(-4.2$ to 6.2$)$ & 0.716 \\
\hline $\begin{array}{l}\text { Per no of more } \\
\text { diagnosis }\end{array}$ & $-0.4(-1.2$ to 0.4$)$ & 0.313 & $-0.7(-1.6$ to 0.1$)$ & 0.079 & $-0.4(-1.2$ to 0.4$)$ & 0.445 & $-0.2(-1.3$ to 0.8$)$ & 0.692 \\
\hline \multicolumn{9}{|l|}{ Gender } \\
\hline Female & Reference & & Reference & & Reference & & Reference & \\
\hline Male & $-0.8(-2.8$ to 1.2$)$ & 0.449 & $0.4(-1.6$ to 2.4$)$ & 0.696 & $-0.3(-1.2$ to 2.1$)$ & 0.792 & $0(-2.6$ to 2.6$)$ & 0.991 \\
\hline Age/ 10 years & $-0.2(-0.9$ to 0.5$)$ & 0.525 & $0(-0.7$ to 0.7$)$ & 0.984 & $-0.4(-1.4$ to 0.6$)$ & 0.317 & $-0.3(-1.2$ to 0.6$)$ & 0.519 \\
\hline
\end{tabular}

Note: Bold figures indicate $p<0.05$.

Abbreviations: $\mathrm{Cl}$, confidence interval; CAP, community-acquired pneumonia; ED, emergency department; HF, acute heart failure; UTI, urinary tract infection; MI, myocardial infarction; DVT/PE, deep vein thrombosis and/or pulmonary embolism; COPD, chronic obstructive pulmonary disease; ED LOS, length of ED stay.

there are limited clinical data suggesting specific timeliness indicators stratified for diagnoses to help improve treatment outcomes. ${ }^{22,42,43}$ While for some diagnoses - such as CAP - a shorter time to antibiotics has been found to be associated with improved survival, such proof is missing for other diseases. Because of this association in CAP patients, the Joint Commission and Centers for Medicare and Medicaid Services advised their national quality standards in 2012 that time to first antibiotic dose should be $<6$ hours. ${ }^{44}$

We also found that increasing age was associated with longer time to treatment and the LOS was increased by 15 minutes for every additional diagnosis, coherent with the complexity of aged, multimorbid patients. This finding suggests that we should pay more attention to the vulnerable population of elderly multimorbid patients and improve treatment pathways to improve their care.

Interestingly, we found a significant shorter LOS in male patients compared to females. The gender disparity is already known in a specified setting (e.g., cardiovascular diseases ${ }^{45}$ or ICU admission ${ }^{46}$ ), but not in general ED wards. It can be speculated that presentation in males and females is different, although we do not have a definite explanation for this finding.
Importantly, in our analysis we found that with increasing time to first physician contact as well as ED LOS, satisfaction with care decreased. Early patient contact and optimal care in the ED thus not only affects morbidity, but also subjective parameters such as quality of care. This is again a strong argument to improve the initial management of patients and focus on these timeliness parameters by all means.

Our study also demonstrates the feasibility of collecting benchmarking data of quality-of-care indices via an electronical system in a tertiary care center in Switzerland. Currently, we use these data for our internal process improvements by quarterly display of data for every single diagnosis. This may inspire other EDs and institutions to also collect and share their quality data to improve transparency of quality in the medical field and start a discussion about time stamps, benchmarks, and quality of care. Improving quality of care not only helps to balance financial incentives (e.g., DRGs) physicians and care givers are exposed to, but should also remain a major commitment for our patients.

Currently, there is a lack of consensus regarding quality measurements and benchmark data reflecting high quality of care and performance in the ED setting. Also, results from observational data, such as ours, are lacking which is 
important to build an evidence base for future initiatives. ${ }^{47,48}$ Further research and consensus with experts and clinicians is thus needed, because the demand for benchmarking is increasingly demanded by patients, health insurances, and physician organizations.

\section{Limitations}

First, clinicians had to document measures for timeliness (e.g., time stamps) during the times of a stressful working shift which may lower their accuracy. In the future, the electronical records may help to get such data easier although times such as "time to first physician contact" may always be dependent on physician inputs. Second, satisfaction with care was asked before ED discharge. Thus, the patients could be in favor of giving higher satisfaction rates than they would give in a more unattributed way of asking, for example, by an anonymous questionnaire and not during speaking to a treating person. Third, not all treatment times were well standardized as several treatments may be used for the same diagnosis (e.g., time to treatment for COPD could be inhalation or intravenous steroid application). Also, some patients may have been treated by paramedics or GPs prior to ED admission and were thus not included in the analysis. Fourth, we did not take into account the number of medical and nonmedical staff available in these EDs to take care of the patients, for example, deficit of caretakers due to illness. Last, we did not consider the bottleneck of in-hospital bed capacity that might have had obstructed transfer from the ED to the medical ward, because our survey closes with the last action of the physician and the delay is not measured by the nurses. All these limitations could have implications in interpreting our results and may limit internal and external validity.

\section{Conclusion}

Within this large cohort of consecutive patients seeking ED care in a tertiary care center in Switzerland, we found time of day on admission to be an important predictor for treatment times. Longer treatment times again predicted low satisfaction with care. These benchmarking data on the quality of care for six main medical diagnoses may help to further compare and improve emergency care in the future.

\section{Acknowledgments}

This work was supported in part by the Swiss National Science Foundation (SNSF Professorship, PP00P3_150531/1, 32003B_135222), the Swiss Academy for Medical Sciences (Schweizerische Akademie der Medizinischen
Wissenschaften [SAMW]), and the Research Council of the Kantonsspital Aarau, Switzerland (1410.000.044). This multidisciplinary and interprofessional trial was only possible in close collaboration of social services (Anja Keller, Regina Schmid), the nursing department (Susanne Schirlo, Petra Tobias), the central laboratory (Martha Kaeslin, Renate Hunziker), medical controlling (Juergen Froehlich, Thomas Holler, Christoph Reemts), IT (Roger Wohler, Kurt Amstad, Ralph Dahnke, Sabine Storost) of the Kantonsspital Aarau, Clinical Trial Unit (CTU), University Hospital Basel (Thomas Fabbro, Stefanie von Felten, Patrick Simon), as well as all participating patients, nurses, and physicians.

\section{Author contributions}

$\mathrm{SB}, \mathrm{BM}$, and PS contributed to the idea for this analysis. SB, $\mathrm{AK}, \mathrm{AC}, \mathrm{TH}, \mathrm{SH}, \mathrm{AH}, \mathrm{UB}, \mathrm{BM}$, and PS were very actively involved in the gathering of data for this study and participated in the development of the manuscript. SB, SH, and PS performed the analysis. All authors contributed toward data analysis, drafting and critically revising the paper, gave final approval of the version to be published, and agree to be accountable for all aspects of the work.

\section{Disclosure}

The authors report no conflicts of interest in this work.

\section{References}

1. Richardson DB. Increase in patient mortality at 10 days associated with emergency department overcrowding. Med J Aust. 2006;184:213-216.

2. Pines JM, Localio AR, Hollander JE, et al. The impact of emergency department crowding measures on time to antibiotics for patients with community-acquired pneumonia. Ann Emerg Med. 2007;50:510-516.

3. Bernstein SL, Aronsky D, Duseja R, et al. The effect of emergency department crowding on clinically oriented outcomes. Acad Emerg Med. 2009;16:1-10.

4. Schuetz P, Albrich WC, Suter I, et al. Quality of care delivered by fee-for-service and DRG hospitals in Switzerland in patients with community-acquired pneumonia. Swiss Med Wkly. 2011;141:w13228.

5. Straubhaar K, Schuetz P, Blum CA, et al. Influence of hospital characteristics on quality of care in patients with community-acquired pneumonia. Swiss Med Wkly. 2016;146:w14337.

6. Thommen D, Weissenberger N, Schuetz P, et al. Head-to-head comparison of length of stay, patients' outcome and satisfaction in Switzerland before and after SwissDRG-Implementation in 2012 in 2012: an observational study in two tertiary university centers. Swiss Med Wkly. 2014;144:w13972.

7. Weissenberger N, Thommen D, Schuetz P, et al. Head-to-head comparison of fee-for-service and diagnosis related groups in two tertiary referral hospitals in Switzerland: an observational study. Swiss Med Wkly. 2013;143:w13790.

8. Kwa P, Blake D. Fast track: has it changed patient care in the emergency department? Emerg Med Australas. 2008;20:10-15.

9. Dinh M, Walker A, Parameswaran A, Enright N. Evaluating the quality of care delivered by an emergency department fast track unit with both nurse practitioners and doctors. Australas Emerg Nurs J. 2012;15:188-194. 
10. Chenoweth D, Martin N, Pankowski J, Raymond LW. A benefit-cost analysis of a worksite nurse practitioner program: first impressions. J Occup Environ Med. 2005;47:1110-1116.

11. Gupta S, Sukhal S, Agarwal R, Das K. Quick diagnosis units - an effective alternative to hospitalization for diagnostic workup: a systematic review. J Hosp Med. 2014;9:54-59.

12. Hospital Inpatient Quality Reporting Program. Available from: wwwqualitynetorg. Accessed: July 13, 2016.

13. Committee on Quality of Health Care in America IoM. In: Crossing the Quality Chasm: A New Health System for the 21st Century. Washington (DC): The National Academies Press; 2001.

14. Committee TESOEECatEW. guidelines for management of ischaemic stroke and transient ischaemic attack 2008. Cerebrovasc Dis. 2008;25(5):457-507.

15. Delinger RP, Levy MM, Rhodes A, et al; Subgroup SSCGCitP. Surviving sepsis campaign: international guidelines for management of severe sepsis and septic shock 2012. 2013;39(2):165-228.

16. Association ACoCAH. ACC/AHA guidelines for the management of patients with ST-elevation myocardial infarction - executive summary. Circulation. 2004;110:588-636.

17. Lee JS, Nsa W, Hausmann LR, et al. Quality of care for elderly patients hospitalized for pneumonia in the United States, 2006 to 2010. JAMA Intern Med. 2014;174:1806-1814.

18. Meehan TP, Fine MJ, Krumholz HM, et al. Quality of care, process, and outcomes in elderly patients with pneumonia. JAMA. 1997;278:2080-2084.

19. Welch S, Augustine J, Camargo CA, Jr., Reese C. Emergency department performance measures and benchmarking summit. Acad Emerg Med. 2006;13:1074-1080.

20. Welch SJ, Asplin BR, Stone-Griffith S, Davidson SJ, Augustine J, Schuur J. Emergency department operational metrics, measures and definitions: results of the Second Performance Measures and Benchmarking Summit. Ann Emerg Med. 2011;58:33-40.

21. Stelfox HT, Straus SE, Nathens A, Bobranska-Artiuch B. Evidence for quality indicators to evaluate adult trauma care: a systematic review. Crit Care Med. 2011;39:846-859.

22. Metersky ML, Sweeney TA, Getzow MB, Siddiqui F, Nsa W, Bratzler DW. Antibiotic timing and diagnostic uncertainty in Medicare patients with pneumonia: is it reasonable to expect all patients to receive antibiotics within 4 hours? Chest. 2006;130:16-21.

23. Kutz A, Florin J, Hausfater P, et al. Predictors for delayed emergency department care in medical patients with acute infections - an international prospective observational study. PLoS One. 2016;11:e0155363.

24. Jung HP, Baerveldt C, Olesen F, Grol R, Wensing M. Patient characteristics as predictors of primary health care preferences: a systematic literature analysis. Health Expect. 2003;6:160-181.

25. Sitzia J, Wood N. Patient satisfaction: a review of issues and concepts. Soc Sci Med. 1997;45:1829-1843.

26. Farley H, Enguidanos ER, Coletti CM, et al. Patient satisfaction surveys and quality of care: an information paper. Ann Emerg Med. 2014;64:351-357.

27. Dinh MM, Enright N, Walker A, Parameswaran A, Chu M. Determinants of patient satisfaction in an Australian emergency department fast-track setting. Emerg Med J. 2013;30:824-827.

28. Sun BC, Adams J, Orav EJ, Rucker DW, Brennan TA, Burstin HR. Determinants of patient satisfaction and willingness to return with emergency care. Ann Emerg Med. 2000;35:426-334.

29. Walsh M, Knott JC. Satisfaction with the emergency department environment decreases with length of stay. Emerg Med J. 2010;27:821-828.

30. Malta M, Cardoso LO, Bastos FI, Magnanini MM, Silva CM. STROBE initiative: guidelines on reporting observational studies. Rev Saude Publica. 2010;44:559-565.
31. Schuetz P, Hausfater P, Amin D, et al. Biomarkers from distinct biological pathways improve early risk stratification in medical emergency patients: the multinational, prospective, observational TRIAGE study. Crit Care. 2015;19:377.

32. Schuetz P, Hausfater P, Amin D, et al. Optimizing triage and hospitalization in adult general medical emergency patients: the triage project. BMC Emerg Med. 2013;13:12.

33. Kutz A, Hausfater P, Amin D, et al. The TRIAGE-ProADM Score for an Early risk stratification of medical patients in the emergency department - development based on a multi-national, prospective, observational study. PLoS One. 2016;11:e0168076.

34. Kutz A, Struja T, Hausfater P, et al. The association of admission hyperglycaemia and adverse clinical outcome in medical emergencies: the multinational, prospective, observational TRIAGE study. Diabet Med. 2017;34:973-982.

36. Sager R, Wirz Y, Amin D, et al. Are admission procalcitonin levels universal mortality predictors across different medical emergency patient populations? Results from the multi-national, prospective, observational TRIAGE study. Clin Chem Lab Med. Epub 2017 Apr 17.

36. Christ M, Grossmann F, Winter D, Bingisser R, Platz E. Modern triage in the emergency department. Dtsch Arztebl Int. 2010;107:892-898.

37. Geelhoed GC, de Klerk NH. Emergency department overcrowding, mortality and the 4-hour rule in Western Australia. Med J Aust. 2012;196:122-126.

38. Kelman S FJ. Performance Improvement and performance dysfunction: an empirical examination of distortionary impacts of the emergency room wait-time target in the English National Health Service. JPART. 2009;19:917-946.

39. McCarthy ML, Zeger SL, Ding R, et al. Crowding delays treatment and lengthens emergency department length of stay, even among high-acuity patients. Ann Emerg Med. 2009;54:492-503 e4.

40. Di Somma S, Paladino L, Vaughan L, Lalle I, Magrini L, Magnanti M. Overcrowding in emergency department: an international issue. Intern Emerg Med. 2015;10:171-175.

41. Capuano F, Lot AS, Sagnes-Raffy C, et al. Factors associated with the length of stay of patients discharged from emergency department in France. Eur J Emerg Med. 2015;22:92-98.

42. Pines JM, Isserman JA, Hinfey PB. The measurement of time to first antibiotic dose for pneumonia in the emergency department: a white paper and position statement prepared for the American Academy of Emergency Medicine. J Emerg Med. 2009;37:335-340.

43. Houck PM, Bratzler DW, Nsa W, Ma A, Bartlett JG. Timing of antibiotic administration and outcomes for Medicare patients hospitalized with community-acquired pneumonia. Arch Intern Med. 2004;164: 637-644.

44. Wunderink RG, Waterer G. Advances in the causes and management of community acquired pneumonia in adults. BMJ. 2017;358:j2471.

45. Chou AF, Wong L, Weisman CS, et al. Gender disparities in cardiovascular disease care among commercial and medicare managed care plans. Womens Health Issues. 2007;17:139-149.

46. Bierman AS. Sex matters: gender disparities in quality and outcomes of care. CMAJ. 2007;177:1520-1521.

47. Schull MJ, Guttmann A, Leaver CA, et al. Prioritizing performance measurement for emergency department care: consensus on evidencebased quality of care indicators. CJEM. 2011;13:300-309, E28-43.

48. Lindsay P, Schull M, Bronskill S, Anderson G. The development of indicators to measure the quality of clinical care in emergency departments following a modified-delphi approach. Acad Emerg Med. 2002;9:1131-1139. 


\section{Publish your work in this journal}

The Open Access Emergency Medicine is an international, peerreviewed, open access journal publishing original research, reports, editorials, reviews and commentaries on all aspects of emergency medicine. The manuscript management system is completely online and includes a very quick and fair peer-review system, which is all

Submit your manuscript here: https://www.dovepress.com/open-access-emergency-medicine-journal

easy to use. Visit http://www.dovepress.com/testimonials.php to read real quotes from published authors. 